\title{
The Embryonic Form of Neural Cell Surface Molecule (E-NCAM) in the Rat Hippocampus and Its Reexpression on Glial Cells Following Kainic Acid-induced Status Epilepticus
}

\author{
Gildas Le Gal La Salle, ${ }^{1}$ Geneviève Rougon, ${ }^{3}$ and Anne Valin ${ }^{2}$ \\ Laboratoire de Physiologie Nerveuse, Départements de 'Neuroanatomie Fonctionnelle et 2 Neurophysiologie Appliquée, \\ CNRS, 91198 Gif sur Yvette, France and 'Université de Luminy, Laboratoire de Biologie de la Différenciation Cellulaire, \\ CNRS, 13288 Marseille, Cedex 9 France
}

The neural cell adhesion molecule (NCAM) changes at the cell surface during development, from highly sialylated forms (embryonic or E-NCAM) to three size classes of less sialylated proteins with apparent molecular mass of 180,140 , and $120 \mathrm{kDa}$ (adult NCAM). In the nervous system, E-NCAM has been localized in developing tissues, where it is thought to play a role in the structuring of neuronal groups and tissue pattern formation.

In the present study a monoclonal antibody that specifically detects E-NCAM was used in immunoblot and immunohistochemical procedures. In developing rat hippocampus, E-NCAM cell expression was found to change according to a precise pattern and persisted until 1 month after birth. It was closely associated with the mossy fiber system, an area known for its sprouting propensity. In adult rats, although immunoreactivity considerably decreases and becomes undetectable by immunoblot analysis, E-NCAM was still found to be associated with a few pyramidal-shaped cells in the innermost part of the dentate gyrus.

In order to acquire some insight into potential histogenetically plastic functions of E-NCAM, in another series of experiments adult rats were treated with kainic acid, a powerful excitotoxic and convulsant glutamate analog eliciting status epilepticus. When these animals were examined for E-NCAM expression, an intense labeling was found associated with glial-like cells, particularly in the hippocampal formation, and corresponding approximately to the reactive gliosis, as confirmed by staining with anti-glial fibrillary acidic protein antibodies. This expression was detectable from about $3 \mathrm{~d}$ following kainic acid administration and persisted for at least 12 weeks; it developed according to an observable spatiotemporal distribution pattern. In animals submitted to amygdala kindling, a nonlesional model of secondarily generalized epilepsy, no such reexpression of E-NCAM was observed. Our observations imply that polysialylation may be a means of identifying neuronal structures capable of plasticity in the CNS. Moreover, intense reexpression of E-NCAM could be a marker of reactive gliosis following brain damage.

Received Apr. 29, 1991; revised Sept. 20, 1991; accepted Oct. 18, 1991.

This work was supported by INSERM Grant 896009 to G. Le Gal La Salle and by grants from Association Française contre la Myopathie and Communaté Economique Europienne to G. Rougon.

Correspondence should be addressed to Dr. Gildas Le Gal La Salle at the above address.

Copyright (C) 1992 Society for Neuroscience $0270-6474 / 92 / 120872-11 \$ 05.00 / 0$
There is increasing evidence that development and stabilization of the neuronal processes related to neurite outgrowth occurring during embryogenesis and histogenesis depend on a variety of specific cell adhesion molecules. During the past few years, particular emphasis has been placed on the neural cell adhesion molecule (NCAM), which has been shown to mediate aggregation of neural cells in vitro, and which is thought to play a key role during the development of the nervous system (for reviews, see Rutishauser and Goridis, 1986; Edelman, 1988; Nybroe et al., 1988; Rutishauser and Jessell, 1988; Rutishauser et al., 1988).

NCAM exists in several structurally distinct isoforms, which are generated from a single gene by alternative RNA splicing and polyadenylation (Walsh, 1988). Further NCAM diversity arises from various posttranslational events.

In the embryonic neural tissue, a striking feature of NCAM is its high content of the unusual $\alpha 2,8$-linked polysialic acid on the extracellular domain of the molecule (Finne et al., 1983). This highly polysialylated form, the so-called embryonic NCAM (E-NCAM), is regionally and developmentally stage-specifically regulated (Edelman and Chuong, 1982; Rougon et al., 1982; Chuong and Edelman, 1984). The degree of sialylation is of particular interest since the binding affinity of the molecule is correlated with its sialic acid content, the less sialylated adult forms being more adhesive (Hoffman and Edelman, 1983; Sadoul et al., 1983). For example, removal of sialic acid by exoor endoneuraminidase treatment increases the adhesive properties of NCAM (Rutishauser et al., 1985). These and other observations have led to the suggestion that developmental or enzymatic embryonic-to-adult form conversion of NCAM may be involved in the stabilization of the processes of terminal neuronal outgrowth and synaptogenesis.

In the light of recent observations, it has been proposed that the polysialic residues of E-NCAM play a role in controlling cell-cell interactions (Rutishauser et al., 1988). This raises the possibility that retention of embryonic features could be associated with morphological plasticity.

In the present study, we hypothesized that plastic changes occurring in experimental or pathological situations in the mature brain require conditions similar to those normally existing during development. There are thus two nonexclusive possibilities: E-NCAM either could be reexpressed in some areas, or could be maintained throughout adult life in cells able to undergo plastic changes. To investigate these possibilities, we used a highly specific monoclonal antibody and analyzed the ex- 
pression of E-NCAM in developing rat hippocampus and following intracerebral injection of kainic acid (KA) or kindling stimulations. KA is a structural analog of glutamate with potent convulsant and cytotoxic properties. When administered into amygdala, it induces short- and long-term effects, including status epilepticus, local and specific remote degenerative lesions, reactive gliosis, sprouting in different subsets of structures, particularly the hippocampus, and late spontaneous recurrent seizures (Ben Ari et al., 1979, 1981; Lothman and Collins, 1981; Cavalheiro et al., 1982; Davenport et al., 1990).

Results presented here show that the transition from E-NCAM to adult forms, the so-called embryonic-to-adult conversion (Friedlander et al., 1984), occurred mainly postnatally in the hippocampal formation, following a precise spatiotemporal pattern and remained expressed in discrete regions even in the adult. We also report the first in vivo evidence for a reexpression of E-NCAM by glial cells in the hippocampus of KA-treated adult animals.

A preliminary report dealing with systemic KA administration has already been presented (Le Gal La Salle and Valin, 1991).

\section{Materials and Methods}

Animals. Adult male Wistar rats weighing around $250 \mathrm{gm}$ at the time of surgery were used for this experiment. Under anesthesia with Equithesin $(4 \mathrm{ml} / \mathrm{kg})$, kainic acid $(1 \mu \mathrm{l}$ in $0.4 \mu \mathrm{l}$ phosphate buffer, $\mathrm{pH} 7.4)$ was injected through a $0.3-\mathrm{mm}$-diameter cannula into the right amygdala (AP5.6, L4.5, H2.2, according to the atlas of Albe-Fessard et al., 1971). Following recovery from anesthesia, the behavior of the animals was observed until completion of true status epilepticus as previously reported (Ben Ari et al., 1979). Animals that did not exhibit the typical pattern of motor seizures were discarded from this study. After variable survival times, ranging between 6 and $12 \mathrm{hr}, 1,2,3,4,7$, and $15 \mathrm{~d}$ and $1,2,3$, and 6 months, the animals were deeply anesthetized with sodium pentobarbital and perfused transcardially with $50 \mathrm{ml}$ of physiological saline followed by a fresh solution of $4 \%$ paraformaldehyde in $0.1 \mathrm{M}$ phosphate buffer, pH 7.4. The brains were then removed, postfixed for about $24 \mathrm{hr}$ in the same fixative, and transferred to a $0.1 \mathrm{M}$ phosphatebuffered $30 \%$ sucrose solution, pH 7.4, for at least $24 \mathrm{hr}$. Sections were then cut using a cryostat apparatus either in the frontal or horizontal planes. A small number of rats also received $\mathrm{KA}$ via the intraperitoneal route at a dose of $10 \mathrm{mg} / \mathrm{kg}$. Age-matched control animals received the same volume of intra-amygdaloid saline instead of KA.

For kindling experiments, animals were prepared with permanently implanted electrodes, stereotaxically placed in the lateral amygdala, that could serve for both stimulation and EEG recordings. As described previously (Le Gal La Salle, 1981), stimulations consisting of a $2 \mathrm{sec}$ train of $60 \mathrm{~Hz}$ square waves of $1 \mathrm{msec}$ duration were applied once a day until three consecutive stage 5 seizures were induced.

Preparation of extracts. Tissues were thawed in $50 \mathrm{~mm}$ Tris- $\mathrm{HCl}$ buffer (pH 8) containing $1 \%$ Nonidet $\mathrm{P} 40$ and $1 \mathrm{mM} \mathrm{MgCl}, 1.25 \mathrm{~mm}$ phenylmethylsulfonyl fluoride, $2000 \mathrm{IU} / \mathrm{ml}$ aprotinin, $40 \mu \mathrm{M}$ leupeptin, $1 \mu \mathrm{M}$ $\alpha 2$ macroglobulin, and $5 \mathrm{~mm}$ iodoacetamide to inhibit proteases. They were homogenized with a mortar equipped with a Teflon pestle and left for $10 \mathrm{~min}$ on ice. The homogenates were centrifuged for $1 \mathrm{hr}$ at 100,000 $\times g$ (Beckman TL100). Protein concentrations were measured in the supernatants and made up to $10 \mathrm{mg} / \mathrm{ml}$. Then, the supernatants were mixed with an equal volume of electrophoresis sample buffer containing $10 \% \beta$-mercaptoethanol and boiled for $3 \mathrm{~min}$. Proteins $(250 \mu \mathrm{g})$ were separated on $7 \%$ SDS-PAGE and electrophoretically transferred to nylon membranes (Nitroscreen TM) $(4 \mathrm{hr}, 0.5 \mathrm{~A})$. Blots were saturated for 2 $\mathrm{hr}$ at $37^{\circ} \mathrm{C}$ with $3 \%$ defatted milk in phosphate-buffered saline (PBS) solution and incubated overnight with 1:1000 dilution of antibodies in PBS/milk. Bound anti-E-NCAM antibody was revealed by incubation of the blot with immunopurified rabbit anti-mouse IgM $(1 \mu \mathrm{g} / \mathrm{ml}$ in PBS/milk, $\left.4 \mathrm{hr}, 20^{\circ} \mathrm{C}\right)$ followed by ${ }^{125} \mathrm{I}$-protein A $\left(0.5 \times 10^{6} \mathrm{cpm} / \mathrm{ml}\right.$, $30 \mathrm{~min}, 20^{\circ} \mathrm{C}$ ) and autoradiography (usually overnight at $-80^{\circ} \mathrm{C} ; \mathrm{Fuji}$ films). Rabbit polyclonal anti-NCAM was directly revealed by incubation of the blot with ${ }^{125}$ I-protein A.

Enzyme. Bacteriophage endosialidase was prepared in the laboratory from bacteriophage PK1A propagated in Escherichia coli US/41 according to the technique of Finne and Makela (1985). For enzymatic assays, the tissue homogenates $(100 \mu \mathrm{l})$ were incubated for $4 \mathrm{hr}$ at $37^{\circ} \mathrm{C}$ under shaking in the presence of $10^{6}$ plaque-forming units (pfu) of the bacteriophage (a quantity found to degrade completely $100 \mu \mathrm{g}$ of colominic acid in $24 \mathrm{hr}$ ).

Immunohistochemistry. Most of the immunohistochemical studies were done on $40 \mu \mathrm{m}$ free-floating sections collected and stored in PBS containing $0.01 \%$ sodium azide. The preparation and the specificity of the site-directed rabbit polyclonal antibody recognizing the $\mathrm{NH}_{2}$-terminal domain of NCAM (Rougon and Marshak, 1986), as well as that for the mouse monoclonal IgM (Rougon et al., 1986) recognizing polymers of NeuAc $\alpha .2-8$ have been described and documented elsewhere. Rabbit antibody against the glial fibrillary acidic protein (GFAP) was purchased from Nordic. For both the adult and embryonic forms of NCAM, immunostaining was performed using the streptavidin-biotinylated peroxidase complex. After a 30 min pretreatment with $0.2 \%$ hydrogen peroxide in PBS to inactivate the endogenous peroxidase and a preincubation with $2 \%$ normal swine serum (NSS) plus $0.2 \%$ Triton X-100 in PBS for $1 \mathrm{hr}$, sections were incubated overnight with the primary antibody at a dilution of 1:500 at room temperature and under slight shaking. Sections were then washed three times in PBS and incubated for $1 \mathrm{hr}$ with anti-species Ig biotinylated whole antibodies (from donkey) diluted 1:200 in PBS plus $2 \%$ NSS. After washing, sections were incubated for $60 \mathrm{~min}$ in streptavidin-biotinylated horseradish peroxidase complex diluted 1:250 in PBS. The last three reactives were purchased from Amersham International Laboratories. GFAP was revealed using the rabbit polyclonal antibody at a 1:500 dilution using the peroxidase-antiperoxidase method. In both cases, peroxidase activity was visualized by incubating the sections in $0.05 \%$ diaminobenzidine and $0.01 \%$ hydrogen peroxide for 5-15 min. Coloration of most of the sections was reinforced by adding nickel sulfate $(0.25 \mathrm{mg} / \mathrm{ml})$ to the chromagen. Finally, sections were mounted on coated glass microscope slides, dehydrated, and embedded in Luxol. Selected sections were also counterstained with cresyl violet. For double labeling, experiments were done with secondary anti-species fluorescent antibodies (fluorescein and rhodamine).

\section{Results}

Animals receiving intra-amygdaloid administration of $\mathrm{KA}$ exhibited a typical and reproducible electroclinical symptomatology as reported previously (Ben Ari et al., 1979; Le Gal La Salle et al., 1984). Briefly, focal limbic seizures appeared soon after dissipation of the anesthetic, rapidly developed into secondarily generalized convulsive seizures, and then culminated in status epilepticus for 12-24 hr. When animals were allowed to survive, following a 2-3 week rest period without further obvious paroxysmal signs, they exhibited spontaneous recurrent seizures for about 1 month in most cases, as already demonstrated for intrahippocampal or systemic KA injections (Pisa et al., 1980; Cavalheiro et al., 1982; Cronin and Dudek, 1988). No epileptic signs were observed following intra-amygdaloid saline injections.

\section{Immunoblotting of brain homogenates}

Homogenates of adult whole hippocampus or posterior cortex were separated on a $7 \%$ polyacrylamide gel and transferred to nitrocellulose. The immunoblots were incubated with the antiE-NCAM monoclonal antibody or with a polyclonal antiserum recognizing all the NCAM isoforms. In tissues from animals maintained in control conditions, E-NCAM was undetectable in the two structures (Fig. 1A, lanes 1 and 2). In contrast, in animals killed $7 \mathrm{~d}$ after KA injection, a prominent broad band was revealed in both structures, although more intense in the hippocampus (lanes 3 and 6). The apparent molecular mass of $200-280 \mathrm{kDa}$ was consistent with that of E-NCAM as reported in previous studies (Rougon et al., 1982, 1986). To assess further the specificity of the staining, homogenates containing positive material were treated with bacteriophage endosialidase, 
and we verified that this treatment completely prevented the immunostaining (lanes 4 and 7). As an additional control we also preadsorbed the monoclonal antibody with colominic acid, a bacterial polymer of $\alpha 2,8$-linked sialic acid (lanes 5 and 8). This treatment also prevented staining. Then, the same blots were desatured and reacted with the site-directed polyclonal anti-NCAM (Fig. $1 B$ ); the three main isoforms of adult NCAM were apparent at 180,140 , and $120 \mathrm{kDa}$, as expected. When lanes $6^{\prime}$ and $7^{\prime}$ were compared we observed that endosialidase treatment removed fuzziness of NCAM bands and the 180 and $140 \mathrm{kDa}$ isoforms became more discrete.

This analysis demonstrates the reexpression of the E-NCAM in the hippocampus and cortex of KA-treated rats. Anatomical localization of this reexpression was further analyzed using immunohistochemical methods.

\section{Immunohistochemical studies}

In the present study particular attention was paid to the hippocampal formation of newborn and adult control rats as well as of KA-treated and kindled animals.

NCAM isoform expression is developmentally regulated and the embryonic form tends to disappear in most brain regions in adult animals. However, as revealed by this study and a few others (Miragall et al., 1988, 1990; Aaron and Chesselet, 1989; Goldowitz et al., 1990; Hekmat et al., 1990; Theodosis et al., 1991), the highly polysialylated form still persists after birth and even throughout adult life in a few brain structures. These observations prompted us to make an immunohistochemical investigation of the hippocampal formation in normal developing rat, since immunoblotting could not be sufficiently sensitive to detect discrete expression of the antigen.

\section{Expression of E-NCAM antigen in the hippocampus of newborn rats}

In the hippocampus of 15-d-old rats, E-NCAM immunoreactivity was almost exclusively localized in regions that correspond to the whole mossy fiber system. As shown in Figure 2, the overall distribution of immunopositive material in newborn animals tends to outline the mossy fiber system and corresponds approximately to the pattern observed in Timm sulfide-stained hippocampal sections of adult rats.

In the dentate gyrus, the inner part of the granule cell layer displays a particularly dense immunoreactivity. This conspicuous but fuzzy band of decorations does not allow positive delineation of the cellular type expressing E-NCAM. The granule cells of the dentate gyrus are probably unlabeled. Many immunoreactive fibers arising from the stained cells are observed crossing the granule cell layer and terminating in stratum moleculare. The internal blade of the lateral granule cell layer displays the strongest immunological signal (enlargement in Fig. $2 C$ ). As shown in Figure 2, $A$ and $B$, a dense band of immunoreactivity is also associated with the suprapyramidal mossy fiber projection in stratum lucidum of regio inferior. Similarly, in the dentate gyrus, fine axons and spherical swellings are quite distinct. The sharpness of the pattern allows easy recognition of the innermost details of structures such as, for example, the infrapyramidal bundle at the base of the hilus.

In 1 month postnatal rats, as illustrated in Figure $2(D$ and $E)$, the overall E-NCAM labeling tends to diminish. A conspicuous but diffuse staining remains in the hilus of the dentate gyrus. A dense and more precise staining becomes detectable in cells at the boundaries of the hilus, beneath the granule cell

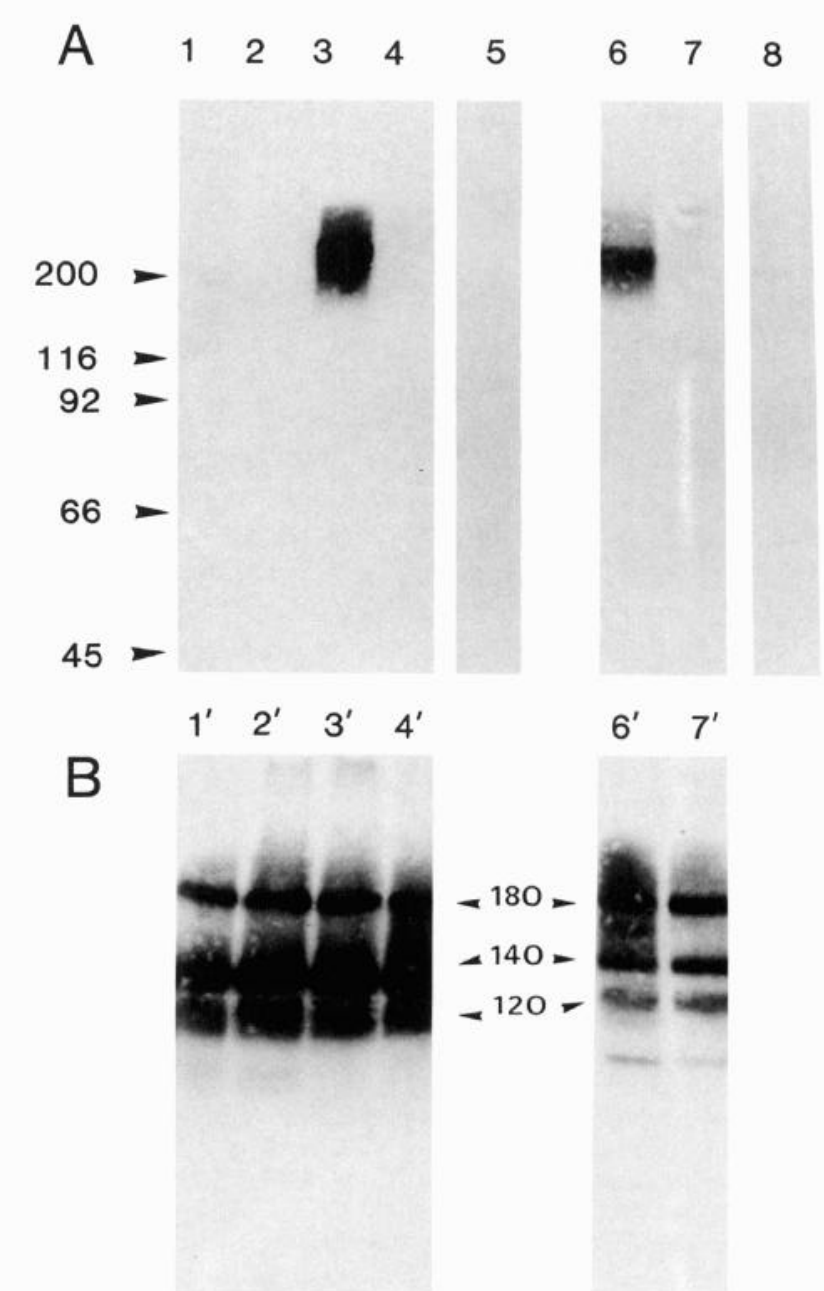

Figure 1. Immunoblots of hippocampal and cortical homogenates revealed by antibodies against E-NCAM and the adult form of NCAM in control and KA-treated rats. $A$, E-NCAM immunoreactivity was not detected by Western blotting in either the hippocampus (lane 1) or the posterior cortex (lane 2) of control adult rats. In contrast, a high amount of E-NCAM-positive material was immunostained in both structures (lanes 3 and 6, respectively) in KA-treated animals killed $7 \mathrm{~d}$ following systemic injection. Immunoreactivity was removed either by incubating the homogenates with endosialidase (lane 4 for hippocampus and lane 7 for cortex) or by preadsorbing the antibody with colominic acid (lanes 5 and 8 , respectively). $B$ shows corresponding lanes reacted with the NCAM polyclonal antibody. The three major adult isoforms are revealed in each structure and unaffected by the enzymatic treatment. The relative position of different molecular mass markers (in KDa) is indicated.

layer. These cells, characterized by a pyramidal-like shape, send extensions that pass between the granule cells and terminate in the molecular cell layer (see higher magnification in Fig. $2 E$ ).

The remaining part of the hippocampus was poorly immunostained, except for a slight labeling of the molecular layer of the subiculum, a structure that is also moderately colored by the Timm sulfide method.

Finally, it is worth stressing here that in the whole hippocampus, no glial cells were labeled, except perhaps in the hilus of the dentate gyrus, where a strong staining of the cells prevented a clear interpretation.

Expression of E-NCAM antigen in normal adult hippocampus In adult animals, as illustrated in Figure 3, labeling of the mossy fiber system was far weaker than in newborn animals. Fibers 

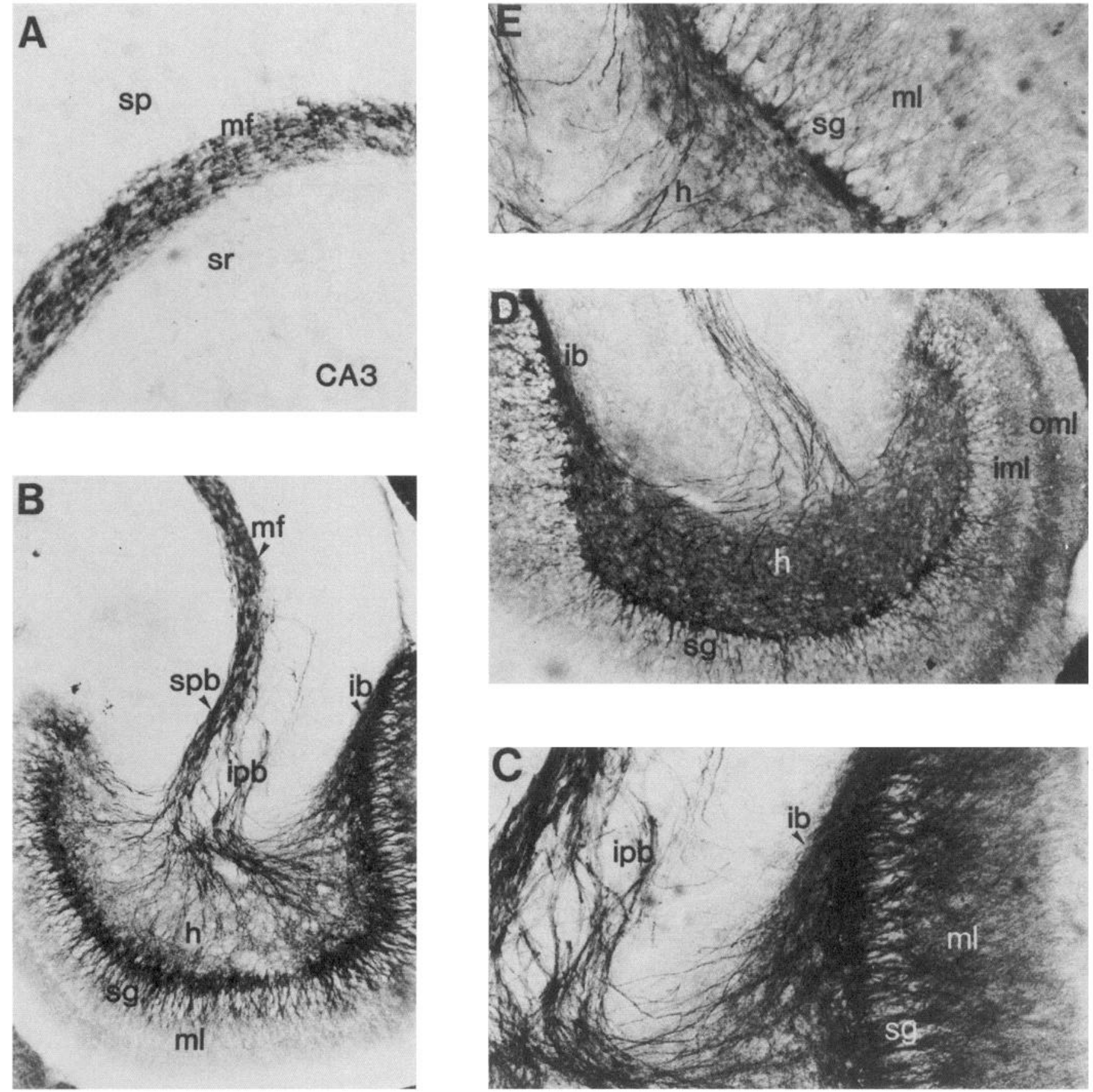

Figure 2. E-NCAM immunoreactivity in newborn control rats. $A-C$, Horizontal sections of a 15-d-postnatal rat hippocampus. Note the intense staining of the entire mossy fiber system, particularly in the inner part of the granule cell layer $[B(\times 50)$ and higher magnification in $C(\times 125)]$, as well as the mossy fiber bundle itself at the level of CA3 $(A, \times 100)$. Dense staining of varicosities in the mossy fibers running along the CA3 pyramidal cells is visible. $D(\times 62)$ and $E(\times 125)$, Horizontal sections in 30 -d-old animals. Note the reduction of staining intensity and the persistence of a strong immunopositivity in the layer located at the boundary of the hilus and the granule cell layer (enlargement in $E$ ). $h$, hilus; $i b$, internal blade of the dentate gyrus; iml, inner molecular cell layer; $i p b$, infrapyramidal bundle; $m f$, mossy fibers; ml, molecular layer; oml, outer molecular cell layer; $s g$, stratum granulosum; $s p$, stratum pyramidale; $s p b$, suprapyramidal bundle; $s r$, stratum radiatum.

are no longer so finely outlined. However, a faint staining persists all along the suprapyramidal bundle and particularly in the hilus. The densest immunoreactivity is still associated with pyramidal-shaped cells, lying just inside the hilar border of the granule cell layer and forming a plexus-like structure in the innermost part of the dentate gyrus (see the enlargement in Fig. $3 B$ ). The shape and the size of these cells, which are larger than the granule cells, make them an identifiable population. Furthermore, they display distinct extensions through the granule cell layer with arborizations in the molecular layer. [According to the literature (Seress and Ribak, 1983; Sloviter, 1987) these cells have features that are consistent with pyramidal basket cells as described in Golgi-stained, Nissl-stained, and immunocytochemical preparations.] As shown in Figure 3, the hilar 

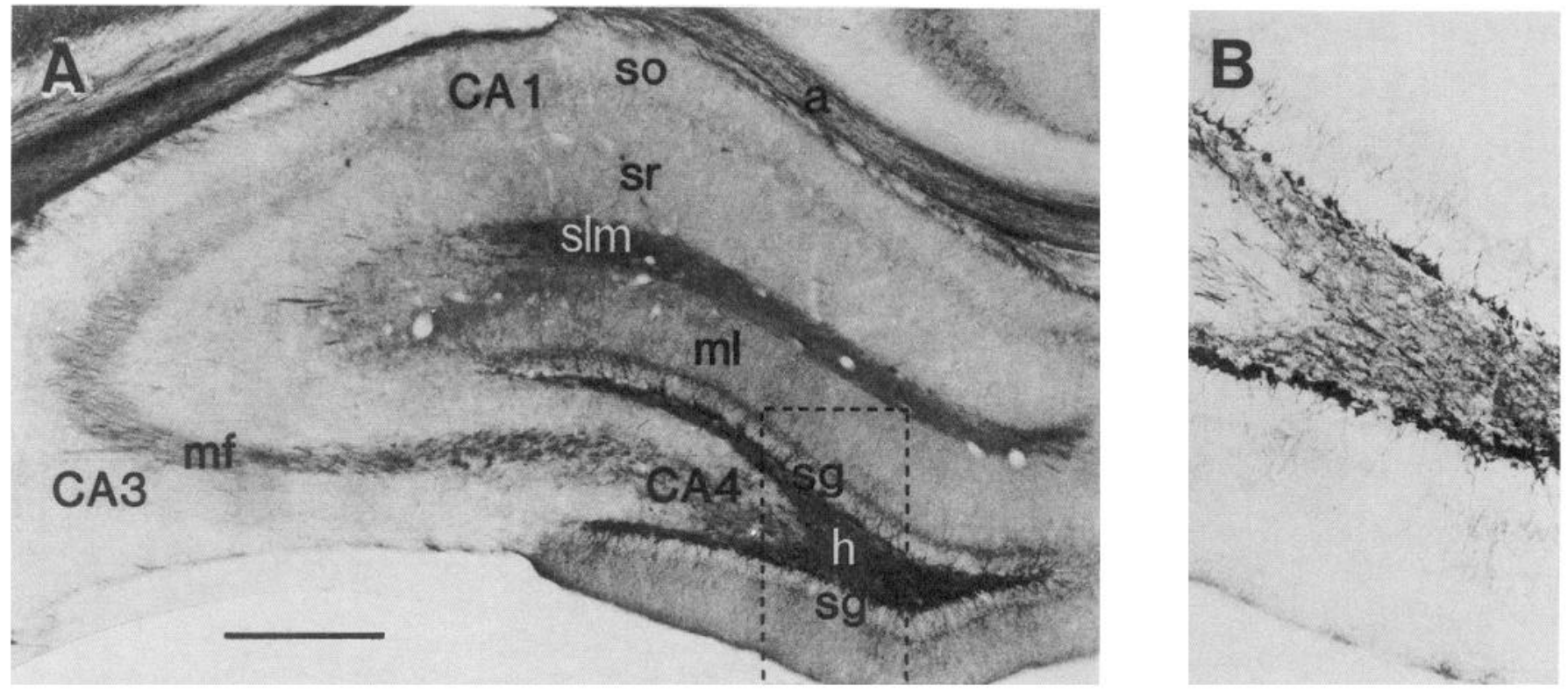

Figure 3. Immunolocalization of E-NCAM in frontal sections of hippocampal formation in control adult rats. $A$, On frontal sections, E-NCAM immunoreactivity is strongly detectable in a fuzzy band lying just beneath the granule cell layer (boxed region). $B$ is an enlargement of this region ( $\times$ 2.5). The hilus of the dentate gyrus, stratum lacunosum-moleculare, and to a lesser extent the mossy fibers display a moderate immunoreactivity. $a$, alveus; $h$, hilus; $m f$, mossy fibers; $m l$, molecular layer; $s g$, stratum granulosum; slm, stratum lacunosum moleculare; so, stratum oriens; $s r$, stratum radiatum. Scale bar, $300 \mu \mathrm{m}$.

region remains densely decorated whereas the stratum moleculare presents only a weak staining. In addition, in regio superiore the stratum lacunosum-moleculare and the alveus appear moderately stained.

In the young animal, as in adult rats, glial cells were never labeled.

\section{Expression of E-NCAM antigen in KA-treated animals}

When compared to the intact rat brain, no significant changes of E-NCAM immunostaining density were observed in the hippocampus of KA-treated animals, until at least 3 or $4 \mathrm{~d}$ after injection of the neurotoxin. In particular, no obvious differences were noted in the mossy fiber system. However, the immunostaining pattern changed markedly after this critical period. Stellate-shaped cells, with long, spiderlike processes and abundant end feet on the cerebrovascular endothelium, appeared heavily stained. The morphological features of these cells are suggestive of glial cells and particularly of astrocytes. Confirmation was provided both by immunostaining serial sections with antisera against the astroglial marker GFAP (Fig. 4A-C) and E-NCAM (Fig. $4 D-F$ ) and by double fluorescent labeling of the same section (data not illustrated).

This observation, supported by immunoblot analysis, implies that positivity on immunoblots observed after KA lesions was mainly due to the expression of the E-NCAM antigen on astrocytes.

The distribution of E-NCAM was area specific and quite similar to that of GFAP. The highest density of immunopositive cells was found within the polymorphic area of the hilar region of the dentate gyrus, the stratum radiatum, and stratum oriens of regio inferiore. A number of stained cells were also discernible in regio superiore stratum radiatum and stratum oriens. As illustrated in Figure 4, a similar distribution was revealed for GFAP-positive cells.
Cells labeled with E-NCAM antibodies exhibit different morphological features according to their location within the hippocampus. Cells with immunoreactive broader soma and coarser, short gliofibrils reside predominantly within the hilus of the dentate gyrus and the stratum oriens. In the radiatum moleculare of the dentate gyrus, stained cells are more elongated and less ramified and have a scanty perinuclear cytoplasm and thinner gliofilaments, which are rather radially orientated. These morphological and regional differences were further confirmed when glial cells were immunostained with GFAP.

As reported in a preliminary account (Le Gal La Salle and Valin, 1991), in animals receiving systemic KA administration the astrocytic reaction was bilateral and the convulsive seizures were more severe, more intense, and more widespread than those resulting from intra-amygdaloid injection.

\section{Spatiotemporal distribution of E-NCAM antigen in the hippocampus of $K A$-treated animals}

Reexpression of E-NCAM displays a specific spatiotemporal distribution. Immunodetection of labeled cells first appears at 3 or $4 \mathrm{~d}$ after injection. At this stage, staining was most conspicuous in the stratum radiatum of $\mathrm{CA} 1$ and $\mathrm{CA} 3$ (Figs. 5, 6). Labeled elements were not yet revealed in the molecular layers or in the hilus of the fascia dentata. Starting from $4 \mathrm{~d}$ postinjection, the number of immunopositive cells increased rapidly, and they invaded almost all the subdivisions of the hippocampus. As shown in Figure 6, morphological differences could be observed according to their location.

After longer intervals following KA injection, stained cells were rare in stratum radiatum of $\mathrm{CA} 1$ and in stratum moleculare of the dentate gyrus. A dense network of labeled cells was located in the CA4 region. Two months after injection, coarse and heavily labeled cells were still present in the hilus and in the stratum radiatum of CA3. With time, the number of labeled cells de- 

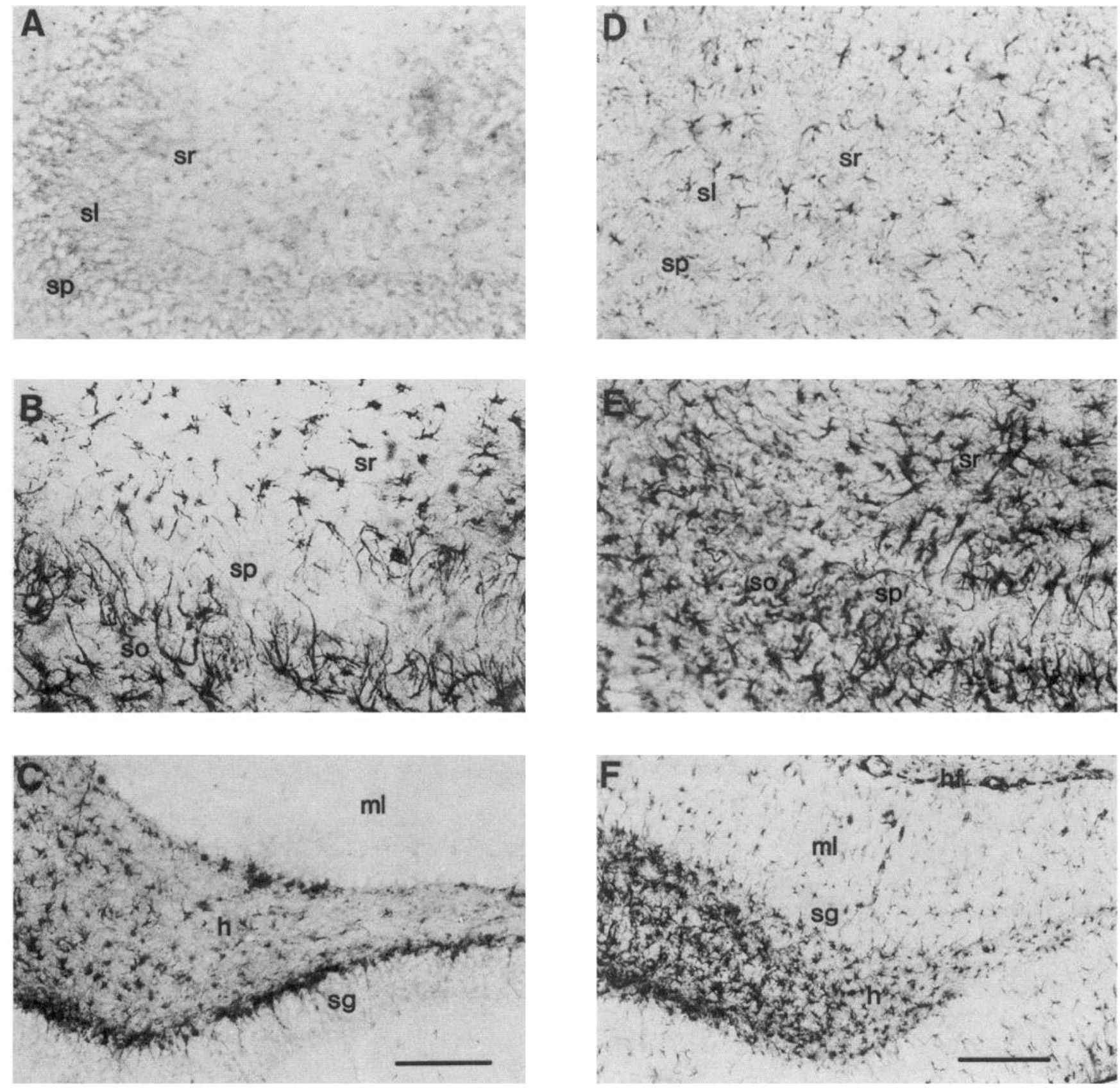

Figure 4. Localization of E-CAM and GFAP immunoreactivity in the dorsal hippocampus of KA-treated rats. $A-C$, Distribution of E-NCAMpositive cells in frontal sections of the dorsal hippocampus. Note the predominant location of these cells in the stratum radiatum and stratum oriens of the regio inferiore ( $B$ as compared to a control animal in $A$ ) as well as in the hilus and the subgranular zone of the dentate gyrus $(C)$. $D-$ $F$, A similar pattern is presented for GFAP-positive cells in comparable sections of control $(D)$ and KA-treated rats $(E$ and $F)$. $h$, hilus; $h f$, hippocampal fissure; $m f$, mossy fibers; $m l$, molecular layer; $s g$, stratum granulosum; $s l$, stratum lucidum; so, stratum oriens; $s p$, stratum pyramidale; $s r$, stratum radiatum. Scale bars, $100 \mu \mathrm{m}$.

creased. Three months after injection, a few stained cells persisted in regions corresponding to the inferior and lateral parts of the dorsal hippocampus.

In each case, the hippocampus contralateral to the injected site presented very few labeled cells. This pattern is in contrast to that observed following systemic administration of KA as presented elsewhere (Le Gal La Salle and Valin, 1991).

Finally, a number of other structures, particularly the limbic cortex, amygdala, septum, and some thalamic nuclei also showed the reexpression of E-NCAM.
Regions with signs of degenerative features, such as the entorhinal cortex, exhibited the most intense and frequent labeling of glial cells.

\section{Expression of E-NCAM antigen in kindling}

To investigate whether reexpression of E-NCAM was related to the epileptic discharge per se rather than to gliosis or brain damage, the immunological study was also conducted on the kindling model of epilepsy, in which no lesions or gliosis had ever been demonstrated. 

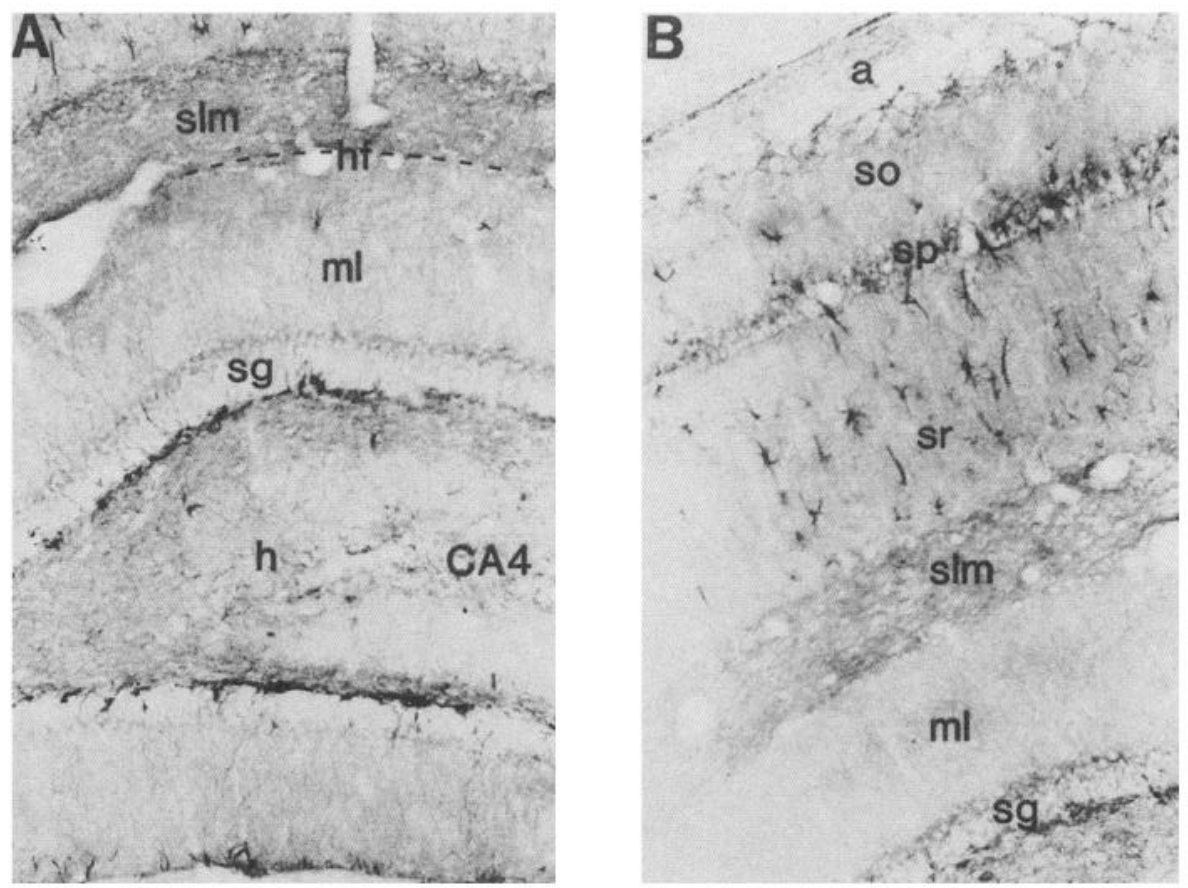

Figure 5. Temporal pattern of E-NCAM-immunopositive cells from $4 \mathrm{~d}$ to 2 months following KA injection. Examples are presented for animals killed at different times following intraamygdaloid saline $(A, 4 \mathrm{~d})$ or $\mathrm{KA}$ administration $(B, 1 \mathrm{~d} ; C, 1$ month; $D, 2$ months). Note the appearance of labeled glial-like cells in stratum radiatum in $B$. At longer intervals cells were encountered mostly in the hilus of the dentate gyrus. $a$, alveus; $h$, hilus; $h f$, hippocampal fissure; $m f$, mossy fibers; $m l$, molecular layer; $s g$, stratum granulosum; $s l m$, stratum lacunosum moleculare; so, stratum oriens; $s p$, stratum pyramidale; $s r$, stratum radiatum. Scale bars, $100 \mu \mathrm{m}$.
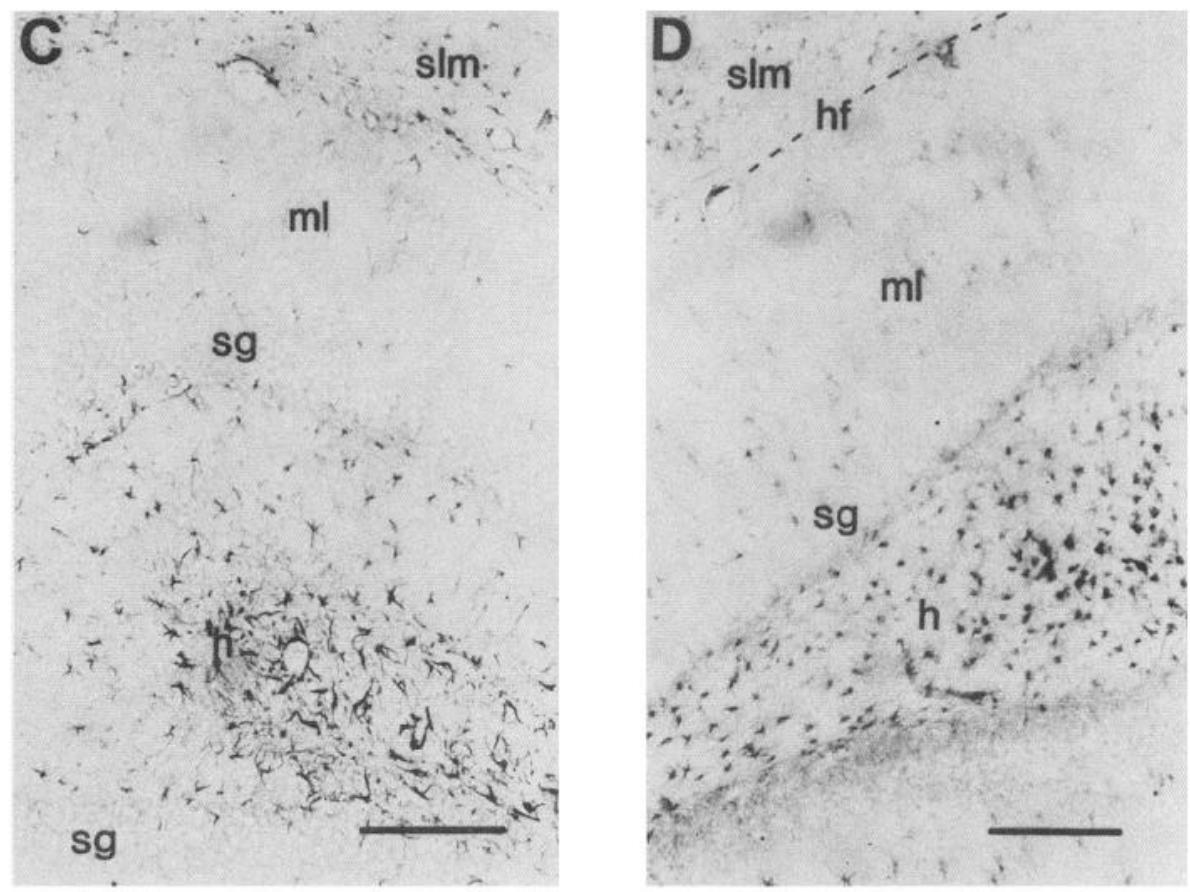

Animals kindled through amygdala stimulation until there had been at least three stage 5 seizures (corresponding to completion of kindling as revealed by expression of secondarily generalized seizures) did not exhibit any visible changes in E-NCAM immunoreactivity. In agreement, modifications of GFAP antigen were not discernible in the hippocampus.

\section{Discussion}

Changes in the sialylation state of NCAM during nervous system development have been well documented, notably by the use of immunoblot techniques (Rougon et al., 1982; Chuong and
Edelman, 1984). The description of monoclonal antibodies specifically recognizing E-NCAM forms from adult forms (Finne et al., 1983; Rougon et al., 1986) has meant that these changes could be described at the cellular level using immunohistochemical techniques. In the present study we focused our attention on the hippocampal formation, since it is a structure with a well-organized cytoarchitecture that can be depicted in both adulthood and during postnatal development, when connections are still maturing (Angevine, 1975). Furthermore, the hippocampus has been widely investigated in studies related to plasticity, memory, ischemia, epilepsy, aging, and several neu- 

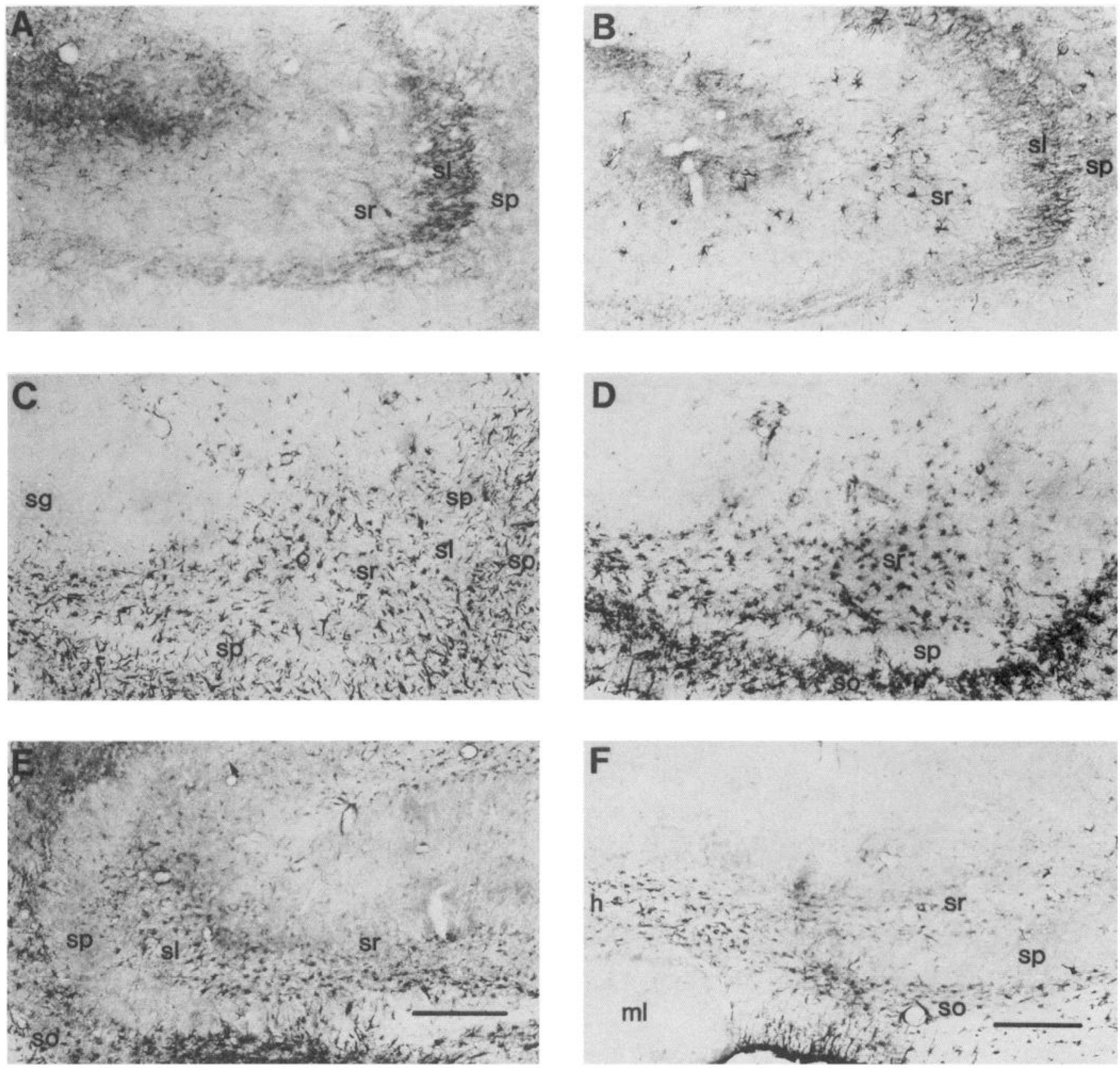

Figure 6. Temporal distribution of E-NCAM-positive cells in the dorsal hippocampus. $A$, Control animal perfused $15 \mathrm{~d}$ following intra-amygdaloid saline injection. Note the absence of stained cells. $B$, Emergence of a few E-NCAM-immunopositive cells $4 \mathrm{~d}$ after KA administration. $C$, One month postinjection, numerous cells are labeled in the stratum radiatum and stratum oriens in the region of CA3. $D$, These cells become more intensely labeled 2 months postinjection. $E$, Three months following KA, E-NCAM immunoreactivity diminishes and tends to disappear (Arrow indicates CA1). E-NCAM-positive cells could still be seen after 4 months only in stratum oriens $(F)$. $h$, hilus; $m l$, molecular layer; $s g$, stratum granulosum; $s l$, stratum lucidum; so, stratum oriens; $s p$, stratum pyramidale; $s r$, stratum radiatum. Scale bars, $100 \mu \mathrm{m}$.

rodegenerative diseases. In order to draw inferences about the general functional principles associated with the expression of E-NCAM, we have studied its cellular localization at the early developmental postnatal stages and in adult KA-treated and kindled rats.

\section{Expression of E-NCAM in the developing and adult hippocampus}

We observed that most of the transition from E-NCAM to less sialylated isoforms occurred postnatally. For example, in 15-d- old animals E-NCAM was mainly associated with the mossy fiber system. This is in agreement with the observation that mossy fibers reach their adult size and morphology between the second and third postnatal week (Gaarskjaer, 1985). Thus, in hippocampus, as in other systems studied, the presence of E-NCAM coincides with the occurrence of major morphogenetic processes taking place in this area. Retention of embryonic features has also been reported for some discrete brain areas or identifiable subpopulations of cells in the CNS of adult animals. This is the case in particular for the olfactory bulb (Miragall et 
al., 1988, 1990), the substantia nigra (Aaron and Chesselet, 1989), the cerebellar cortex (Hekmat et al., 1990), the optic nerve and retina (Bartsch et al., 1990), and in less detail the hippocampal formation (Goldowitz et al., 1990).

We have shown that some cells forming a plexus-like structure at the border between the hilus and granule cell layer retained E-NCAM throughout adult life. This observation may be in line with the report that a few granule cells are able to proliferate in the mature brain (Bayer et al., 1982) and therefore implies that E-NCAM could be associated with proliferating cells. Immunohistochemical studies conducted with antibodies detecting all the isoforms of NCAM (Goldowitz et al., 1990) also showed that this area is the latest to express NCAM, while the outermost granule cells of the dentate gyrus are the earliest. The exact identification of these E-NCAM-positive cells awaits further experimentation. Their location, within or just subjacent to the granule cells, may have a functional significance.

\section{Seizure-induced brain damage is associated with E-NCAM reexpression}

Probably the most significant finding of the present study is the demonstration of a massive reexpression of E-NCAM in hippocampus and, to a lesser extent, in cerebral cortex, a few days following KA-induced status epilepticus. To our knowledge, this is the first in vivo description of a "reconversion" toward E-NCAM expression in the CNS. KA injection induces a complex reaction that includes the occurrence of electroencephalographical and long-lasting behavioral epileptic manifestations. The occurrencc of paroxysmal activity alone does not seem sufficient per se to induce reexpression of E-NCAM since there is no such effect in kindled animals. Thus, E-NCAM reexpression is very likely associated with remote brain damage induced by long-lasting status epilepticus. On the other hand, this brain damage may be attributed to an excess of excitation rather than to the direct cytotoxic effect of KA. Indeed, brain damage induced by KA mimics, at least partially, that observed in the temporal lobe in human epileptics as well that occurring in rat after prolonged electrical stimulation of the perforant path, the main excitatory input of the hippocampus. At the histological level, seizure-induced hippocampal damage is accompanied by numerous phenomena such as brain edema, cell loss, gliosis, and reactive sprouting.

\section{$E-N C A M$ retention or reexpression is associated with plasticity}

In KA-treated animals, sprouting was observed from neurons either directly or in the immediate vicinity of cells expressing E-NCAM in late developing or adult animals. In rodent hippocampus, mossy fibers are known for their propensity to sprout easily in several situations, including KA administration (Nadler et al., 1980; Ben Ari et al., 1981). This tends to support the hypothesis that retention of E-NCAM expression by neurons may be related to their regenerative capability. However, reexpression of E-NCAM was not demonstrated in the kindling model, although sprouting, even if less prominent, was also observed in the supragranular cell layer of kindled animals (Sutula et al., 1988; Repressa et al., 1989).

It is interesting to compare these observations with the data of Landmesser et al. (1990) on the intramuscular cell branching of developing chick motoneurons. These authors reported that neuromuscular activity blockade resulted in nerve trunk defasciculation and increased branching associated with an increase in axonal E-NCAM level revealed by immunostaining. This clearly represents evidence that changes in synaptic activity produced morphological changes mediated through a specific cell surface component. Moreover, some discrete areas of the CNS able to undergo morphological changes under physiological or pathological circumstances in adulthood have been shown to continue to express E-NCAM throughout adult life. This is the case for the hypothalamo-hypophysial system (Theodosis et al., 1991), and the interpeduncular nucleus (Aaron and Chesselet, 1989). Given the continually increasing evidence for neuronal plasticity in the adult brain, it is possible that E-NCAM functions to some extent in mature neurons to modulate the cellcell contacts required for neuronal rearrangements and synapse formation. Therefore, evidence for polysialylation of NCAM may become a useful marker for neuronal systems capable of plasticity.

\section{$E-N C A M$ reexpression is associated with reactive gliosis}

Immunolabeling using antibodies against E-NCAM and GFAP unambiguously showed that E-NCAM staining was associated with glial cells. Although confirmation will require further studies, the morphological aspect of labeled cells is consistent with an involvement of reactive astrocytes (see Gall et al., 1979; Miller et al., 1986). Furthermore, the spatiotemporal distribution of stained cells was apparently parallel to that of astrogliosis as revealed by GFAP staining. We cannot exclude the possibility that E-NCAM staining could be attributable to a phagocytosis of degenerating E-NCAM-expressing fibers by neighboring glial cells. However, this is very unlikely since the localization of E-NCAM-positive glial cells and E-NCAM-positive fibers are not correlated. Thus, our observations indicate that E-NCAM reexpression in the CNS could be a suitable marker for reactive gliosis.

Although in normal animals E-NCAM has been reported as usually associated with neurons, there are some examples of its expression by astrocytes in adulthood. This is the case for the glial cells in the optic nerve (Bartsch et al., 1990) and pituicytes in the hypothalamo-hypophyseal system (Theodosis et al., 1991). Thus, it is likely that in vivo, these cells have the potential to synthesize NCAM as has been demonstrated in vitro (Noble et al., 1985).

From the conceptual point of view, the present result would tend to indicate that reexpression of E-NCAM may be part of a process that reactivates developmental mechanisms involved in remodeling of tissue structures. However, we did not observe any expression of E-NCAM by astrocytes in the hippocampus at the developmental stages we studied. The cellular and molecular sequence of events that contribute to the expression of polysialic units on NCAM is not yet understood. In our model of KA-treated rats it is already established that expression of the cellular c-fos oncogene in the dentate granule cells is the first known modification to occur (Le Gal La Salle, 1988). This is followed by an increased expression of NGF in the same structure (Gall et al., 1991). Other later events such as production of additional growth factors, interleukins, or enzyme modifcations may play a role in contributing to the reestablishment of immature environment. An alternative, but not exclusive hypothesis, is that E-NCAM may be expressed by astrocytes generated from resting precursors during reactive gliosis. It is known that cell division occurs during this phenomenon, and it is thus likely that a population of astrocytes might transiently cxpress E-NCAM. This would parallel what is observed in muscle diseases, in which E-NCAM expression is only detectable in 
regenerating myoblasts derived from activation of satellite cell precursors, whereas degenerating fibers reexpress NCAM but not the polysialylated form (Figarella-Branger et al., 1990). Even if this expression of E-NCAM is aberrant because it occurs in a cellular environment different from that existing during normal development, it is likely that it could be beneficial for neuronal regeneration and brain damage repair. Among the various functions that are assigned to glia, one is thought to stimulate and guide neuritic outgrowth (Gage et al., 1988). In particular, in vitro experiments have shown that embryonic and early postnatal astrocytes are an effective cellular substrate for rapid neurite extension, and it is proposed that immature but not adult glia can promote growth during regenerative processes (Smith et al., 1986, 1990). Moreover, a role for polysialylation of NCAM has recently been demonstrated for neurite outgrowth of chick retinal ganglion cells on 3T3 transfected with NCAM (Doherty et al., 1990).

\section{References}

Aaron LI, Chesselet MF (1989) Heterogeneous distribution of polysialylated neuronal-cell adhesion molecule during post-natal development and in the adult: an immunohistochemical study in the rat brain. Neuroscience 28:701-710.

Albe-Fessard D; Stutinsky F, Libouban S (1971) Atlas stéréotaxique du diéncéphale du rat blanc. Paris: CNRS.

Angevine JB (1975) Development of the hippocampal region. In: The hippocampus (Isaacson R, Pribram K, eds), pp 66-90. London: Plenum.

Bartsch V, Kirchhoff F, Schachner M (1990) Highly sialylated N-CAM is expressed in adult mouse optic nerve and retina. J Neurocytol 19: 550-565.

Bayer SA, Yackel JW, Puri PS (1982) Neurons in the rat dentate gyrus granular layer substantially increase during juvenile and adult life. Science 216:890-892.

Ben Ari Y, Lagowska J, Tremblay E, Le Gal La Salle G (1979) A new model of focal status epilepticus: intra-amygdaloid application of kainic acid elicits repetitive secondarily generalized convulsive seizures. Brain Res 163:176-179.

Ben Ari Y, Tremblay E, Riche D, Ghilini G, Naquet R (1981) Electrographic, clinical and pathological alterations following systemic administration of kainic acid, bicuculline and pentetrazole: metabolic mapping using the deoxyglucose method with special reference to the pathology of epilepsy. Neuroscience 6:1361-1391.

Cavalheiro EA, Riche D, Le Gal La Salle G (1982) Long-term effects of intrahippocampal kainic acid injections in rats: a method for inducing spontaneous recurrent seizures. Electroencephalogr Clin Neurophysiol 53:581-589.

Chuong CM, Edelman GM (1984) Alterations in neural cell adhesion molecules during development of different regions of the nervous system. J Neurosci 4:2354-2368.

Cronin J, Dudek FE (1988) Chronic seizures and collateral sprouting of dentate mossy fibers after kainic acid treatment in rats. Brain Res 474:181-184.

Davenport CJ, Brown WJ, Babb TL (1990) Sprouting of GABAergic and mossy fiber axons in dentate gyrus following intrahippocampal kainate in the rat. Exp Neurol 109:180-190.

Doherty P, Cohen J, Walsh FS (1990) Neurite outgrowth in response to transfected N-CAM changes during development and is modulated by polysialic acid. Neuron 5:209-219.

Edelman GM (1988) Morphoregulatory molecules. Biochemistry 27: 3533-3543.

Edelman GM, Chuong CM (1982) Embryonic to adult conversion of neural cell adhesion molecules in normal and staggerer mice. Proc Natl Acad Sci USA 79:7036-7040.

Figarella-Branger D, Nedelec J, Pellissier JF, Boucraut J, Bianco N, Rougon G (1990) Expression of various N-CAM isoforms and their highly polysialylated counterparts in diseased human muscles. J Neurol Sci 98:21-36.

Finne J, Makela H (1985) Cleavage of the polysialosyl units of brain glycoproteins by a bacteriophage endosialidase. J Biol Chem 260: $1265-1270$.
Finne J, Finne U, Deagostini-Bazin H, Goridis C (1983) Occurrence of alpha 2-8 linked polysialosyl units in a neural cell adhesion molecule. Biochem Biophys Res Commun 112:482-487.

Friedlander DR, Brackenbury R, Edelman GM (1984) Conversion of embryonic form to adult forms of N-CAM in vitro: results from de novo synthesis of adult form. J Cell Biol 101:412-419.

Gaarskjaer FB (1985) The development of the dentate area and the hippocampal mossy fiber projection of the rat. J Comp Neurol 241 154-170.

Gage FH, Olejniczak P, Armstrong DM (1988) Astrocytes are important for sprouting in the septohippocampal circuit. Exp Neurol 102:2-13.

Gall C, Rose G, Lynch G (1979) Proliferative and migratory activity of glial cells in the partially deafferented hippocampus. J Comp Neurol 183:539-550.

Gall C, Murray K, Isackson PJ (1991) Kainic acid-induced seizures stimulate increased expression of nerve growth factor mRNA in rat hippocampus. Mol Brain Res 9:113-123.

Goldowitz D, Barthels D, Lorenzon N, Junblut A, Wille W (1990) NCAM gene expression during the development of cerebellum and dentate gyrus in the mouse. Dev Brain Res 52:151-160.

Hekmat A, Bitter-Suermann D, Schachner M (1990) Immunocytological localization of the highly polysialylated form of the neural cell adhesion molecule during development of the murine cerebellar cortex. J Comp Neurol 291:457-467.

Hoffman S, Edelman GM (1983) Kinetics of homophilic binding by embryonic and adult forms of the neural cell adhesion molecule. Proc Natl Acad Sci USA 80:5762-5766.

Landmesser L, Dahm L, Tang J, Rutishauser U (1990) Polysialic acid as a regulator of intramuscular nerve branching during embryonic development. Neuron 4:665-667.

Le Gal La Salle G (1981) Amygdaloid kindling in the rat: regional differences and general properties. In: Kindling 2 (Wada JA, ed), pp 31-47. New York: Raven.

Le Gal La Salle G (1988) Long-lasting and sequential increase of c-fos oncoprotein expression in kainic acid-induced status epilepticus. Neurosci Lett 88:127-130.

Le Gal La Salle G, Valin A (1991) Réexpression de la forme embryonnaire de NCAM dans l'hippocampe de rat après état de mal épileptique induit par un neurotoxique. C R Acad Sci 312:43-47.

Le Gal La Salle G, Shen KF, Feldblum S (1984) Rôle de l'hippocampe, de l'amygdale et de la substance noire dans l'évolution des états de mal épileptiques induits par injection d'acide kainique chez. le rat. Rev EEG Neurophysiol Clin 14:235-240.

Lothman EW, Collins RC (1981) Kainic acid induced limbic seizures: metabolic, behavioral, electroencephalographic and neuropathological correlates. Brain Res 218:299-318.

Miller RH, Abney ER, David S, Ffrench-Constant C, Lindsay R, Patel $\mathrm{R}$, Stone J, Raff MC (1986) Is reactive gliosis a property of a distinct subpopulation of astrocytes? J Neurosci 6:22-29.

Miragall F, Kadmon G, Husmann M, Schachner M (1988) Expression of cell adhesion molecules in the olfactory system of the adult mouse; presence of the embryonic form of N-CAM. Dev Biol 129:516-531.

Miragall F, Kadmon G, Faissner A, Antonicek H, Schachner M (1990) Retention of $\mathrm{J} 1 /$ tenascin and the polysialylated form of the neural cell adhesion molecule (N-CAM) in the adult olfactory bulb. J Neurocytol 19:899-914.

Nadler JV, Perry BW, Cotman CW (1980) Selective reinnervation of hippocampal area CAl and the fascia dentata after destruction of CA3-CA4 afferents with kainic acid. Brain Res 182:1-9.

Noble M, Albrechtsen M, Moller C, Lyles J, Bock E, Goridis C, Watanabe M, Rutishauser U (1985) Glial cells express N-CAM/D2.CAM like polypeptides in vitro. Nature 316:725-728.

Nybroe O, Linnemann D, Bock E (1988) NCAM biosynthesis in brain. Neurochem Int 12:251-262.

Pisa M, Sanberg PR, Corcoran ME, Fibiger HC (1980) Spontaneously recurrent seizures after intracerebral injection of kainic acid in rat: a possible model for human temporal lobe epilepsy. Brain Res 200: $481-487$.

Repressa A, Le Gal La Salle G, Ben Ari Y (1989) Hippocampal plasticity in the kindling model of epilepsy in rats. Neurosci Letts 99: 345-350.

Rougon G, Marshak D (1986) Structural and immunological characterization of the amino terminal domain of mammalian neural cell adhesive molecules. J Biol Chem 261:3396-3401. 
Rougon G, Deagostini-Bazin H, Hirn M, Goridis C (1982) Tissue and developmental stage-specific forms of a neural cell surface antigen linked to differences in glycosilation of a common polypeptide. EMBO J 1:1239-1244.

Rougon G, Dubois C, Buckley N, Magnani JL, Zollinger W (1986) A monoclonal antibody against meningococcus group $B$ polysaccharides distinguishes embryonic from adult N-CAM. J Cell Biol 103:24292437.

Rutishauser U, Goridis C (1986) NCAM: the molecule and its genetics. Trends Genet 2:72-76.

Rutishauser U, Jessell TM (1988) Cell adhesion molecules in vertebrate neural development. Physiol Rev 68:819-857.

Rutishauser U, Watanabe M, Silver J, Troy FA, Vimr ER (1985) Specific alteration of NCAM-mediated cell adhesion by an endoneuraminidase. J Cell Biol 101:1842-1849.

Rutishauser U, Acheson A, Hall A, Mann D, Sunshine J (1988) The neural cell adhesion molecule (N-CAM) as a regulator of cell-cell interactions. Science 240:53-57.

Sadoul R, Hirn M, Deagostini-Bazin H, Rougon G, Goridis C (1983) Adult and embryonic mouse neural cell adhesion molecules have different binding properties. Nature 304:347-349.
Seress L, Ribak CE (1983) GABAergic cells in the dentate gyrus appear to be local circuit and projection neurons. Exp Brain Res 50:173182 .

Sloviter RS (1987) Decreased hippocampal inhibition and a selective loss of interneurons in experimental epilepsy. Science 235:73-76.

Smith GM, Miller RH, Silver J (1986) Changing role of forebrain astrocytes during development, regenerative failure, and induced regeneration upon transplantation. J Comp Neurol 251:23-43.

Smith GM, Rutishauser U, Silver J, Miller RH (1990) Maturation of astrocytes in vitro alters the extent and molecular basis of neurite outgrowth. Dev Biol 138:377-390.

Sutula T, Xiao-Xian H, Cavazos J, Scott G (1988) Synaptic reorganization in the hippocampus induced by abnormal functional activity. Science 239:1147-1150.

Theodosis DT, Rougon G, Poulain DA (1991) Retention of embryonic features by an adult neuronal system capable of plasticity: embryonic N-CAM in the hypothalamo-neurohypophysial system. Proc Natl Sci Acad USA 88:5494-5498.

Walsh FS (1988) The N-CAM gene is a complex transcriptional unit. Neurochem Int 12:262-267. 